\title{
O SOLICITANTE DE REFÚGIO E A SOBERANIA MODERNA: A IDENTIDADE NA DIFERENÇA
}

\author{
Ana Luiza Lacerda
}

Instituto e Relações Internacionais, Pontifícia Universidade Católica-Rio,

Rio de Janeiro, RJ. Brasil. E-mail <analvmdl@gmail.com>

Carlos Frederico P. S. Gama

Instituto de Relações Internacionais, Universidade Federal do Tocantins (IRI/UFT) e

Instituto de Relações Internacionais (IRI/PUC)-Rio. Rio de Janeiro, RJ. Brasil.

E-mail<carlosfredericopdsg@gmail.com>

http://dx.doi.org/10.1590/ 0102-6445053-080/97

\section{A ótica da fronteira}

At the crossing of the border between the night and day Where the lost and lonely find their twilight sway And the curse of their existence is the loneliness they feel

Where waking up with a stranger's the only thing from them that's real. ${ }^{1}$

The Mission, "Swan Song”, 2013.

Assistimos, em 2015, a cenas dramáticas nas relações internacionais. Crianças mortas nas praias da Turquia durante travessia do mar com familiares e outras pessoas em busca de abrigo na Europa. Multidões acossadas por forças policiais e militares no interior da União Europeia sendo "escoltadas" de um país (Hungria) para outro (Áustria) - a unificação tinha posto fim às limitações de mobilidade intrabloco. Países tão diversos quanto Austrália, Grécia e Brasil se

1 "É na travessia da fronteira, entre a noite e o dia, / Que perdidos e solitários vão ao encontro de seu crepúsculo / Pressentem que sua existência toma o rumo da solidão / A única certeza é de que amanhecerão como estrangeiros" (tradução livre dos autores). 
voluntariam para acolher dezenas de milhares de pessoas obrigadas a sair de suas casas na Síria em meio à guerra civil naquele país. Esses dramas compartilham um elemento: são protagonizados por refugiados, pessoas que cruzam fronteiras internacionais fugindo de abusos de direito e/ou conflitos (Betts e Loescher, 2011, p. 1).

A identidade daqueles que circulam forçosamente pelo espaço internacional está inserida em uma "geopolítica da mobilidade", que exibe formas de poder bastante assimétricas na relação do ser humano com o fluxo e o movimento (Hyndman, 2000, p. 30). Enquanto a fronteira é, para alguns, um portão aberto, um canal sem filtro, para outros, ela é um cadeado recriado e reforçado a cada passo. Nesse canal, avistam-se identidades negociadas; o poder soberano busca disciplinar a diferença decidindo sobre corpos humanos, sobre suas dignidades pendentes de exclusões e inclusões. A fronteira pode ser vista como um dos espaços de exibição 54 privilegiada desse poder que perpassa identidades, que as cria e é criado por elas. Carregar um passaporte é carregar uma identidade cidadã, uma representação soberana que interfere nas relações de um indivíduo, nas decisões tomadas sobre ele e seu destino. Não carregar um passaporte é estar exposto ao vazio, à falta de garantias, ao limbo e à vulnerabilidade. No momento atual - de globalização que facilita o fluxo de capitais, informações e de algumas pessoas -, acumulam-se indivíduos que ficam de fora, olhares à margem da legitimação soberana.

Este artigo incide sobre a situação de refugiados, imigrantes ilegais e solicitantes de refúgio. Pretende realocá-los no espaço da política moderna, que busca outros caminhos que não o da violência e exclusão. O foco recai especialmente sobre os solicitantes de refúgio no Brasil. Conceitos de identidade e diferença, advindos de diversas contribuições recentes da literatura sobre relações internacionais, são tomados para auxiliar a compreensão de um fenômeno 
que afeta concretamente milhões de pessoas, valorizando assim a experiência do cotidiano como espaço político que pode nos permitir acessar processos políticos globais.

A escolha do solicitante de refúgio, no momento da solicitação, não é infundada. Reconhece-se aqui o problema das categorias associadas à figura do imigrante, tais como o imigrante irregular, o imigrante ilegal, os sem documentos (sans papier), os solicitantes de refúgio (asylum seekers) e refugiados. No caso brasileiro, ao contrário do que ocorre na Europa, o termo "imigrante ilegal" não é amplamente utilizado, sendo aplicado juntamente com o "irregular", principalmente no caso dos trabalhadores bolivianos em São Paulo. O sujeito escolhido aqui - que está sob uma nomenclatura legal fundamentada na legislação internacional de proteção aos refugiados - é aquele que está no momento de total sujeição aos desejos do Estado, que está no limbo entre a expulsão e a proteção definitiva. Em termos de status legal, os imigrantes ilegais já estão obrigados a se retirar do país, sua expulsão já fora determinada; os irregulares são aqueles que precisam normalizar sua situação, seja ela qual for; os refugiados, por sua vez, são aqueles que já têm sua proteção legalmente e internacionalmente reconhecida; enquanto os solicitantes de refúgio estão no meio de todas essas categorias legais, pairando sobre todos os regimes de proteção, por vezes contidos em um centro de detenção, por outras portando apenas um documento que não revela seu destino, nem de expulsão, nem de reconhecimento.

Nossa opção em abordar indivíduos abarcados num status legal específico nos leva a não tratar diferentes formas de identificação individual em um mesmo grupo, principalmente considerando-se aqui o papel fundamental da experiência do cotidiano como espaço político de multiplicidades. É premissa em nosso trabalho deixar cada indivíduo falar, a fim de questionar um efeito colateral frequente nas menções à "questão migratória" e sua "gover- 
nança”. O uso de categorias e modelos interpretativos, nos quais o sujeito desaparece, produz massas amorfas, sem voz e individualidades, em meio às quais só se veem fluxos, tendências e outras estatísticas (Malkki, 1996). Categorias, no marco deste artigo, servem para designar um status legal, uma nomenclatura perante a lei - nomenclatura esta que define o momento vivido pelo indivíduo na solicitação de refúgio -, e para demonstrar como essa categorização perpassa discursos da sociedade brasileira.

O texto ora apresentado se beneficia da experiência de campo da coautora no Conare (Comitê Nacional para Refugiados $)^{2}$. A partir dessa experiência - centrada no início dos processos de solicitação de refúgio -, exploraremos importantes aspectos da situação de refúgio no plano global, oriunda da mobilidade "indesejada", problematizando visões sobre soberania e fronteira, usualmente contempladas em termos de encontros entre um pressuposto "eu" e um deferi56 do "outro". O processo pelo qual passa o solicitante de refúgio é uma complexa negociação de identidades, desencadeada no cruzamento da fronteira e culminando com as entrevistas no Conare. Indo além, abordaremos a questão do enfrentamento e do encontro de identidades vividos pelo solicitante de refúgio: a convivência cotidiana com os cidadãos, a interpretação destes sobre os imigrantes e a contínua exclusão por eles vivida - expondo assim a complexidade do cotidiano dessas pessoas e sua precariedade como sujeitos políticos (porém, não desprovidos de agência).

Considerando a adição da categoria legal de proteção dos haitianos especificamente no Brasil, vale ressaltar que apenas mencionaremos esse caso no decorrer do argumento, visto que o instituto de proteção dessas pessoas é diferente do refúgio - conforme a Convenção de Genebra de 1951

\footnotetext{
2 Ana Luiza Lacerda acompanhou entrevistas com solicitantes de refúgio na Cáritas Arquidiocesana do Rio de Janeiro, entre 2012 e 2013.
} 
- não havendo ligação com o documento de solicitante ou com o processo de apresentação na Polícia Federal e perante o Conare, conforme será explorado. Porém, nos discursos trazidos sobre a figura do solicitante de refúgio há referências aos haitianos, como nas declarações feitas em Brasileia, Estado do Acre - o que revela confusão no discurso popular sobre quem é o refugiado e quais são suas necessidades específicas (mostrando a falta de clareza sobre o tema do refúgio no Brasil, fruto de relativo desinteresse na opinião pública por questões relacionadas aos refugiados [Gama, 2015]).

\section{Fronteiras entre soberano e solicitante de refúgio}

Os vários momentos do processo de solicitação de refúgio - da declaração na fronteira até a última entrevista no Conare - são obstáculos com que o solicitante se depara, novas fronteiras a ultrapassar. Questões de identidade envolvidas estão diretamente relacionadas com o conceito de soberania.

A nosso ver, a soberania como conjunto de práticas sociais que a definem e a viabilizam nunca deve ser tomada como dada, nem tampouco repetida sem questionamento, por ser sempre contingente e processual, nem fixa nem imutável, fruto de práticas contra as quais se pode lutar e resistir. No espaço precário do refúgio global, a soberania é contestada e resistida como uma forma de poder (Edkins e Pin-Fat, 2005, p. 2).

Para explorar o assunto, utilizamos a contribuição de teóricos como Robert B. J. Walker, William Connolly, Didier Bigo e David Campbell - associados com diferentes perspectivas pós-estruturalistas das relações internacionais -, bem como de autores que se dedicam especificamente ao tema dos refugiados, tais como Jennifer Hyndman, Lisa Malkki, Jenny Edkins, Veronique Pin-Fat, Emma Haddad, Nevzat Soguk e Barry Hindess, além de uma pletora de autores brasileiros que trabalham nessas interfaces. 
Perspectivas críticas das relações internacionais abordam a gênese do ambiente internacional. No dizer de Walker, o ambiente internacional resulta de uma solução moderna para diversos problemas políticos humanos: diferença versus similaridade, unidade versus particularidade. $\mathrm{O}$ ambiente internacional se funda numa discriminação simbólica no espaço (cidadão/amigo versus estrangeiro/inimigo) e no tempo (civilizado/ordeiro versus bárbaro/desordeiro). Essas clivagens são reproduzidas simbolicamente pela concatenação de muitos Estados que manifestam diferentes formas de vida num único sistema internacional, considerado "anárquico". E, nesse interim, diversas formas de vida são excluídas, bem como a passagem entre espaços e tempos (entre unidades soberanas) é vedada simbolicamente e dificultada no repertório de práticas internacionais institucionalizadas. A aspiração moderna de abarcar a totalidade da existência humana é medida em múltiplas exclusões.

Análises políticas contemporâneas são caracterizadas tanto por ideais regulativos da convergência de todas as fronteiras e limites em linhas que distinguem o nacional do internacional, o interno do externo, o amigo do inimigo, e assim por diante, quanto por sugestões de que a maior parte do que é agora mais significativo politicamente toma a forma de práticas complexas de fronteirização dentro, através e entre as linhas de discriminação temporais e espaciais (Walker apud Lelandais, 2008, p. 257) ${ }^{3}$.

Em termos da mobilidade internacional, a soberania pode ser observada em seu aspecto territorial, como autoridade sobre um território e um grupo de indivíduos: uma soberania que é vivida na fronteira ao separar, excluir, classificar. A soberania reside, então, no Estado territorial-

3 Todas as citações originalmente em inglês foram traduzidas pelos autores. 
mente definido; opera dentro deste e busca o controle de uma população através de performances cotidianas que a recriam constantemente. Sendo necessário o território, é a fronteira que o constituirá, delimitando o espaço da autoridade e o espaço da identidade. O princípio da soberania não apenas deriva do território, mas também sugere que é necessário pensar as fronteiras como delineadoras da possibilidade da própria política em um espaço e um tempo (Walker, 1993, p. 175). O território marca, com a delimitação de sua fronteira, o aspecto da política moderna como política espacial, que distingue o participante/sujeito/cidadão do Estado daqueles que estão do lado de fora (Walker, 2005, p. 306). A soberania expressa a fronteira entre o dentro e o fora, enquadrando o entendimento do espaço político, organizando e classificando, e delegando características a determinada identidade de pertencimento, uma identidade coletiva formada em detrimento de outras.

Fronteiras só possuem significado ao marcar o que atravessam e separam; são linhas múltiplas de divisão e manifestação de aporias, atravessando não apenas dois espaços, mas separando diferentes identidades associadas a diferentes espaços e noções de pertencimento (Soguk, 2007, p. 296). O "eu" e o "outro" são categorias que, no limite do território estatal, se tornam requisitos para a existência do próprio Estado, categorias que se multiplicam em diferentes identidades, mas que reproduzem a dicotomia cidadão versus alienígena.

É nesse binário que reside a cidadania como ferramenta de fronteirização, ou a fronteirização como necessária para a constituição do cidadão, visto que cidadania é a ligação entre indivíduo e Estado via pertencimento ao território (Haddad, 2008, p. 54). A cidadania é parte central no governo moderno de populações, como uma questão de relações domésticas entre o Estado e seus cidadãos ou como um signo da diferença, aconselhando vários Estados 
e instituições internacionais sobre a qual Estado em particular dado indivíduo pertence. O fazer da cidadania está imbricado na manutenção de fronteiras territoriais entre os Estados, regulando o movimento dos que entram e saem e dos que circulam à deriva (Hindess, 2005). O controle de corpos humanos através das fronteiras se torna mecanismo central das concepções de ordem política na modernidade (Gama e Tabak, 2012).

Após explorar brevemente a questão da soberania, a construção e o papel da fronteira e a relevância da cidadania, abordaremos a identidade do solicitante de refúgio no Brasil.

\section{Entrelinhas da soberania: o solicitante de refúgio no Brasil}

O status dos refugiados no Brasil é um tema de intenso interesse acadêmico. Fluxos de refugiados são considerados uma das matrizes da formação da nação brasileira des-

60 de o século XVI (Amaral e Fusco, 2005). Por outro lado, políticas públicas de acolhida de refugiados (bem como de migrantes) foram alvo de extensas críticas por seu caráter seletivo. A acolhida obedecia a uma tentativa sistemática de "branqueamento" da população por parte das elites políticas nacionais, especialmente durante o Império e a Era Vargas (Lesser, 1994), priorizando solicitantes "não africanos" e "não asiáticos". Déficits na cidadania concedida aos recém-acolhidos são elementos recorrentes em análises das políticas públicas para refugiados no Brasil (Moulin, 2011), suscitando contestações que se articulam com lutas mais amplas por direitos civis (Moulin e Nyers, 2007). Outras dimensões abordadas são a criação de comitês de refugiados em unidades federativas e a problemática integração das pessoas nas cidades onde se refugiaram (Moreira e Baeninger, 2010).

$\mathrm{O}$ interesse pelos refugiados nas relações internacionais do Brasil é mais recente, como é relativamente nova a própria área de estudos. A posição dos governos brasileiros, 
em geral favoráveis à acolhida de refugiados durante crises internacionais, fez o país ser considerado, desde os anos de 1950, um "modelo" na América do Sul (Jubilut, 2006). Entretanto, apenas após a redemocratização (Moreira, 2010) e o fim da Guerra Fria é que se utilizou sistematicamente a acolhida a refugiados para projetar uma nova imagem internacional do país (Cervo, 2002), aderindo à maioria dos instrumentos internacionais de direitos humanos e direito humanitário (Verwey et al., 2000) e acolhendo refugiados de todos os cantos do mundo (Moreira, 2005, p. 71). O uso dos refugiados para fins de política externa, porém, também suscita críticas, tendo em vista os números de acolhida do Brasil vis-à-vis outros países emergentes (Gama, 2015).

Uma vez que o foco deste artigo recai sobre os solicitantes de refúgio no Brasil, é importante delinear o regime brasileiro de proteção de refugiados. Atualmente, o país é indicado pelo ACNUR (Alto Comissariado das Nações Unidas para os Refugiados) como exemplo na América Latina de proteção aos refugiados, de acordo com a amplitude de seu quadro legal de proteção e ambiente de cooperação entre os órgãos governamentais responsáveis pelo trato do instituto do refúgio, o ACNUR e a sociedade civil, com destaque para a ONG Cáritas Arquidiocesana. Essa inserção no regime internacional está presente desde 1951, com a participação brasileira no Comitê Consultivo do ACNUR, e, em 1960, com a ratificação da Convenção de 1951 (Moreira, 2007). Em 1992, o Brasil, ainda que não possuísse uma lei organizada com a definição, passou a reconhecer a definição de refugiado fornecida pela Declaração de Cartagena, incluindo em seu entendimento a grave violação de direitos humanos como razão para o refúgio, tendo aceitado, entre 1992 e 1994, a entrada de 1.200 angolanos que saíam de um país em aguda crise (Moreira, 2007). Em 1997, o Brasil cria sua legislação, ampliando assim a proteção internacional 
com a Lei $n^{\circ} 9.474$ (Jubilut, 2007; Brasil, 1997), onde se encontra a definição de refugiado:

Art. $1^{\circ}$ Será reconhecido como refugiado todo indivíduo que: I - devido a fundados temores de perseguição por motivos de raça, religião, nacionalidade, grupo social ou opiniões políticas encontre-se fora de seu país de nacionalidade e não possa ou não queira acolher-se à proteção de tal país; II - não tendo nacionalidade e estando fora do país onde antes teve sua residência habitual, não possa ou não queira regressar a ele, em função das circunstâncias descritas no inciso anterior; III - devido a grave e generalizada violação de direitos humanos, é obrigado a deixar seu país de nacionalidade para buscar refúgio em outro país.

O processo de solicitação de refúgio no Brasil é um pro62 cesso tripartite (Jubilut e Apolinário, 2008), envolvendo o governo, o ACNUR e a sociedade civil.

A Lei $n^{\circ} 9.474 / 97$ estabelece o processo de solicitação de refúgio e cria o Conare, cujas competências incluem analisar o pedido de refúgio, determinar a perda da condição de refugiado, dar apoio jurídico, coordenar as ações no âmbito da proteção dos refugiados e aprovar resoluções normativas à referida lei (Brasil, 1997). O Conare é um órgão deliberativo, constituído por um representante do Ministério da Justiça, que o preside, um do Ministério das Relações Exteriores, um do Ministério do Trabalho, um do Ministério da Saúde, um do Ministério da Educação e Desporto, um representante da Polícia Federal e um representante da organização não governamental responsável pela proteção dos refugiados no país, papel atualmente desempenhado pela Cáritas Arquidiocesana (Brasil, 1997). O ACNUR, nas reuniões do Comitê, é observador, podendo intervir, porém sem poder de voto. 
Com a estruturação do Conare, a Lei segue para regular o procedimento de solicitação de refúgio. Inicialmente, resolve-se que o pedido de refúgio deve ser realizado perante autoridade competente (a Polícia Federal), seja na entrada no país ou posteriormente, o que é bastante comum, após a procura do auxílio para o processo na Cáritas nos estados do Rio de Janeiro ou São Paulo. Ressalta-se que a partir do momento em que o indivíduo é reconhecido como solicitante de refúgio, sua entrada no país, ainda que ilegal, deixa de constituir crime (ACNUR, 2012). A intenção de aplicar um pedido de refúgio, feita inicialmente na Polícia Federal, é oficializada a partir do Termo de Declaração seguindo a Resolução Normativa ${ }^{\circ}$ 1, de 1999. Esse primeiro documento relata os dados básicos do solicitante e requisita a descrição, bastante sucinta, dos motivos pelos quais o solicitante saiu de seu país de origem, fornecendo também uma forma de documento de identificação até que o Protocolo Provisório, em breve detalhado, seja expedido.

O procedimento seguinte se dá no âmbito da Cáritas Arquidiocesana. Nessa etapa, será preenchido novo Questionário para Solicitação de Refúgio, que requer detalhes mais aprofundados sobre a saída do solicitante de seu país, tais como: declarações sobre participação em grupos políticos, envolvimento em situações de violência, possibilidades de risco em caso de retorno ao país de origem, se foi preso, se sofreu violência física, enfim, circunstâncias da vida do solicitante que resultaram na necessidade da fuga.

É a partir dessa apresentação na Cáritas e a entrega desse Questionário que será requisitado e expedido pelo Conare o Protocolo Provisório, que funcionará como documento de identidade para o solicitante de refúgio, que, com ele, poderá tirar CPF e Carteira de Trabalho, tendo validade de 90 dias, com possibilidade de prorrogação no caso do processo de solicitação não ter sido finalizado dentro desse prazo (ACNUR, 2012). Na Cáritas, expedido o Questionário, é 
também realizada entrevista com um advogado, que age em favor do solicitante ao conversar sobre seu caso e para informá-lo sobre o processo que se seguirá, fazendo isso dentro do previsto pela legislação nacional do refúgio. Esse advogado elaborará parecer contendo o resumo da entrevista realizada e usará elementos jurídicos e informações sobre a fundamentação dos fatos narrados pelo solicitante para então sugerir a decisão a ser tomada.

A última etapa que completa os documentos que irão para a deliberação sobre o caso é a entrevista com o Conare. A entrevista é feita pessoalmente em uma sede da Cáritas ou por telefone nos casos em que não haja essa organização na cidade em que o solicitante se encontra. Ela é realizada com um funcionário do Comitê e segue um roteiro parecido com o Questionário já preenchido; a grande diferença é que as informações não são escritas pelo solicitante, elas passam pela interpretação do entrevistador. A entrevista é 64 confidencial e nela qualquer declaração pode ser feita, se comprometendo o solicitante, segundo pede o ACNUR e o governo, a falar a verdade.

O momento legal posterior ao limbo da solicitação é a decisão final do Conare, na qual se encontra a avaliação do pedido no Comitê e a notificação ao solicitante. O pedido de refúgio passa para o julgamento das sete instituições que deliberarão em plenário (o ACNUR não tem poder de voto) e uma decisão, devidamente fundamentada, deve ser emitida. No caso de o pedido ser deferido, nova situação será iniciada para o solicitante. Assinando o Termo de Responsabilidade e recebendo o Registro Nacional de Estrangeiros, o indivíduo se comprometerá a cumprir todos os seus deveres como refugiado e, daí em diante, as medidas procedimentais serão tomadas para a emissão da cédula de identidade de refugiado. No caso do pedido ser indeferido, a situação de vulnerabilidade se estende. Recebendo a decisão negativa, o solicitante tem direito a requerer recurso 
contra o resultado, apresentando novas justificativas para seu desejo de tornar-se refugiado. Mais uma vez, o solicitante permanece no escuro com o Protocolo Provisório até que seu processo seja julgado, e, enquanto isso, passa o tempo sem saber para onde vai, por vezes renovando mais uma vez o Protocolo. Em caso de indeferimento final ao recurso, o solicitante se encontrará no fim da reta, submetendo-se ao Estatuto do Estrangeiro e tendo que abandonar o país sem mais tardar.

Resumo desse processo no diagrama da Figura 1.

Figura 1

Trajeto percorrido pelos solicitantes de refúgio no Brasil

\begin{tabular}{|l|l|}
\hline Polícia Federal & $\begin{array}{l}\text { Pedido de Refúgio } \\
\text { Termo de Declaração }\end{array}$ \\
\hline
\end{tabular}

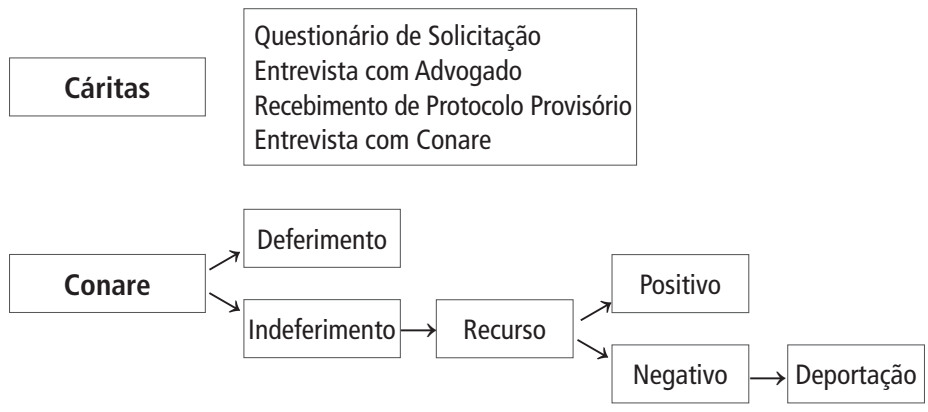

\section{Da legalidade à identidade: sujeições e soberanias}

Saindo do âmbito legal do refúgio no Brasil, o primeiro aspecto da identidade do solicitante de refúgio vem à tona na interação inicial no cruzamento da fronteira, na chegada de um novo indivíduo em uma zona de controle de um novo soberano, manifesta logo que seu passaporte - por vezes, inexistente - é demandado por um funcionário do governo (no Brasil, a Polícia Federal). É no momento que este indivíduo assina um papel pedindo refúgio que ele se 
torna um solicitante, com uma nova identidade, que começa a ser exercida e reconhecida, existente apenas à medida que é praticada, o que ocorre a cada encontro e enfrentamento. A autoproclamação do solicitante e a resposta do funcionário do governo são o momento em que se inicia o conhecimento daquele indivíduo para o novo soberano, que passa a controlar o seu destino em processo de concessão ou negação da nova identidade, em um novo processo de subjetificação (Foucault, 1982). O cruzamento de uma fronteira e a apresentação perante um novo soberano distinguem essa identidade. No instante em que essa pessoa se propõe a tentar uma nova vida, um processo de negociação de sua identidade se instaura, processo este que durará até que um novo documento, um novo reconhecimento, menos vulnerável, lhe seja conferido (literalmente, assinado por um representante do novo soberano). Essa assinatura reitera o caráter soberano do poder político e a discricio66 nariedade do ato de conferir refúgio. Séculos atrás, Hobbes (1991 [1642-1651]) apontava como sujeito "o ser humano capaz de assinar o próprio nome”. Na nova subjetivação, um ser humano se torna portador de direitos de cidadania por decisão alheia.

A questão da identidade do solicitante de refúgio no cruzamento da fronteira e em seu processo de solicitação perante o Conare pode ser tratada como uma questão do encontro com o outro, um "enigma of otherness". O termo cunhado por William Connolly (1989, p. 326) se refere ao "descobrimento" da América pelos espanhóis, numa analogia válida no sentido da estranheza e rejeição do encontro. Connolly exibe diferentes leituras que são permitidas com o momento do encontro e o desafio à identidade do "eu" que tem lugar quando a interação com a diferença questiona certezas de identidade pura e verdadeira, de pertencimentos, crenças e formas de vida corretas, morais e absolutas. $\mathrm{O}$ autor compara diferentes estratégias de lidar com a diferença 
representadas, respectivamente, por Cristóvão Colombo e por Bartolomé de Las Casas, mostrando a adoção da superioridade e subjugação do outro por parte do primeiro e a tentativa de entendimento e conversa do segundo. Dentro do espectro do encontro, o "outro" é tratado mediante conquista ou conversão. No primeiro caso, é um bárbaro ameaçador que precisa ser eliminado. No segundo caso (assimilação), o "outro" é visto como selvagem, inocente, um primitivo que precisa ser "salvo", convertido à religião do colonizador. Podemos abordar o momento do encontro do imigrante com o cidadão funcionário da fronteira em seu complexo de estranhamentos, que expõe o limite da interação, a vertigem do reconhecimento e do embate entre uma identidade que se crê verdadeira e a interpretação do outro por ela, a partir de como

[...] o enigma do outro e o conhecimento dele, do outro e da constituição da identidade pessoal, do outro e o estranhamento dele, do outro e da consolidação da identidade coletiva, do outro e da dependência dele, do outro e dos paradoxos da integridade ética (Connolly, 1989, p. 323).

Esse enfrentamento prossegue durante todo o processo de solicitação de refúgio e a cada declaração, a cada documento e entrevista, o mesmo encontro é presenciado, sulcando cada vez mais essas identidades através da desconfiança, da criação de verdades e da constante negação da alteridade, à medida que as decisões soberanas se acumulam. As entrevistas nesse momento do processo também podem ser vistas como fronteiras entre soberano e solicitante.

O grande problema aqui é o poder que esse funcionário, que "lê" o outro, tem sobre o destino do imigrante. Mais do que incoerências e fragilidades de identidades que 
se assumem verdadeiras em teoria, saltam aos olhos os efeitos dessas formas de identificação sobre a vida de outros, os pequenos efeitos cotidianos de aparentes verdades tidas por universalizantes, frequentemente excludentes e eivadas de senso de superioridade. Os solicitantes se tornam vulneráveis nas mãos de pequenos representantes do soberano - se tornam sujeitos às interpretações e a "exceções que são agora feitas como um modo contínuo de ação, e que podem ser feitas pela máquina burocrática e seus funcionários, tanto quanto pelos grandes soberanos" (Walker, 2005, p. 23).

Assim, durante todo o processo de solicitação de refúgio, essas pessoas permanecem provisoriamente abrigadas nos interstícios soberanos, sem saber o que virá no futuro, sem saber qual a nova identidade que poderão exercer.

O outro lado do problema da identidade do solicitante de refúgio - que também abarca imigrantes irregulares e refugiados já reconhecidos - é a interpretação, a relação do 68 "senso comum" local com o outro estrangeiro, diferente, que carrega uma identidade quase totalmente desconhecida para a coletividade, principalmente no caso brasileiro.

A intepretação desse senso comum, os "grandes medos de uma sociedade” (Bigo, 2002) são corporificados na figura do imigrante, que fantasmagoricamente e vicariamente traz o medo do terrorismo, o medo da miséria, o medo de quem "rouba empregos", de quem traz doenças. Essas projeções estereotípicas configuram uma visão única de anormalidade e patologia (Bigo, 2002). Esse outro - o imigrante ilegal, o refugiado ou o solicitante de refúgio - é considerado um agente poluidor, que, por desafiar a ordem que a fronteira deveria impor, deve ser contido e limpado, tanto na mais violenta forma dos centros de detenção, quanto na exclusão e rejeição na vida cotidiana (Haddad, 2008, p. 119). Assim, perante a sociedade, a construção do imigrante enquanto indesejado ocorre quando é incitado um discurso, como o de que há um "surto" de refugiados, a irrupção de uma fonte 
de "problemas" que precisam ser resolvidos, problemas que devem canalizar institucionalmente a busca por soluções (Soguk, 1999). Esse discurso emite uma verdade que é regulada institucionalmente - é produzida e incitada tanto como forma de preencher uma necessidade de verdade comum, quanto como ferramenta de poder político. Essa verdade é regulada e exposta por grandes aparelhos políticos e de comunicação, no debate político e confronto social (Foucault, 2010, p. 13).

O discurso sobre a interpretação da identidade de outros dentro de um Estado é sempre diferente: em cada contexto, temos diferentes "eus" e diferentes "outros". Tanto em termos de medidas para "solucionar o problema" da imigração ilegal, quanto em termos da reação de cidadãos ao outro, há consideráveis variações entre a situação de imigrantes e refugiados na Europa, Estados Unidos e Brasil, havendo sempre, em maior ou menor escala, a rejeição, a exclusão, o medo de alguma forma de ameaça.

Ao fim da Guerra Fria, se seguiu uma crise de representação na qual o outro, ameaças e inimigos, para ensejar constantemente a identidade do eu, deixaram de ser facilmente encontráveis. Para David Campbell, esse cenário trouxe instabilidades para o "interesse nacional" dos Estados Unidos, associado com a unidade nacional; é nesse contexto que o multiculturalismo é visto como potencial ameaça (Campbell, 1996, p. 163). O medo da "balcanização" e do "multiculturalismo" enfatiza visões ameaçadoras da instabilidade que identidades diferentes podem trazer, rearticula noções de responsabilidade e identidade (Campbell, 1996).

No caso do Brasil, o fim da Guerra Fria foi seguido de maior receptividade aos refugiados. O país recém-redemocratizado se via como um global player e mantinha aspirações de liderança regional e internacional. Acolher refugiados mostrava que o Brasil era um país de braços abertos e 
tolerante - o que, no entanto, se choca com os relatos dos solicitantes e com as dificuldades dos novos habitantes após lhes ser concedido o refúgio, como enfatizado anteriormente neste artigo.

Campbell associa o fim da Guerra Fria com uma crise identitária e nacional nos Estados Unidos, país que o autor caracteriza como marcado por uma "retórica de fronteiras não resolvidas" e de constante mudança de arranjos culturais internos, necessitando de múltiplas estratégias para estabelecer suas condições de possibilidade de existência (Campbell, 1996, p. 164). Nos Estados Unidos, processos de domesticação e estabilização de identidades do lado de dentro são enfatizados, através do mecanismo do interesse nacional e de uma política externa que produz diferenciação e exclusão, enfatizando e reiterando "ameaças" externas (Campbell, 1996, p. 169). A política externa é, nesse caso, uma prática que afirma e cria ideais de nação, uma política 70 que estabelece condições de possibilidade para a existência de uma nação (Campbell, 1996, p. 167).

No Brasil, ainda que o "evangelism of fear", termo cunhado por Campbell (1996), não seja comparável com o existente nos Estados Unidos, nos últimos anos tentativas de afirmação de uma identidade nacional a partir do contraste com outras identidades ganha força mediante um discurso que contrapõe alegados "valores brasileiros" à presença de imigrantes, especialmente os haitianos. O fim da Guerra Fria tornou mais visíveis as lacunas de cidadania entre os "naturais" do Brasil e os acolhidos.

Nesse sentido, a contribuição mais importante de Campbell é sua noção da política externa como prática de fronteirização ligada às identidades. Em chave similar, nosso artigo propõe que a solicitação de refúgio constitui uma modalidade de fronteirização. Fronteirização não implica apenas uma relação entre dois Estados soberanos, na qual indivíduos ocupam a linha de fronteira. A solicitação de refúgio assume feições 
de fronteirização à medida que identidades são negociadas entre populações através de fronteiras que produzem assimetrias identitárias e de agência política. De outra sorte, o cenário brasileiro difere em muito do caso norte-americano. Nosso artigo abordará, doravante, efeitos da fronteirização no cotidiano dos solicitantes de refúgio no Brasil.

\section{Trocando em miúdos: o refúgio como negociação do cotidiano na linha de fronteira}

Analisando discursos do senso comum no Brasil, Lacerda (2013) salienta manifestações cotidianas de exclusão que repercutem na sociedade brasileira quando se referem a solicitantes de refúgio, refugiados, imigrantes ilegais e, atualmente, haitianos.

No Brasil, perguntando a algumas pessoas sobre suas opiniões sobre a vinda de imigrantes para o país, ouvi que "será mais um miserável", "vem gastar nosso dinheiro", "vai virar mais um criminoso, por que não tem trabalho aqui”. [...] Há a questão da saúde, na qual os imigrantes são acusados de trazer doenças, ou terem hábitos de higiene que podem fazer mal aos cidadãos. Em uma reportagem com um comerciante de Brasileia, no Acre: "Ninguém sabe a procedência desse povo", "Sabemos que o país deles tem epidemia de cólera, hepatite, aids. Eles não têm controle de nada, não fazem prevenção sexual". Outro afirma que "Só tenho medo das doenças que eles trazem junto". Ainda, há a visão da segurança da sociedade, da coesão nacional. No Brasil há o estranhamento das culturas que chegam, com os africanos e os poucos muçulmanos. Mais uma declaração da situação de Brasileia no Acre: "Eles já estão tão à vontade aqui que começaram até a fazer magia negra, vodu, aquelas coisas que eles fazem lá no país deles”, em referência à violação de um túmulo no cemitério local, que na verdade foi feita por estudantes da cidade (Lacerda, 2013, p. 44). 
Problematizar o senso comum é importante para exibir o acúmulo de práticas que não são novas, mas que se aplicam a cada vez mais casos e, com a chegada de mais imigrantes, se tornam mais plasmadas em aspectos do cotidiano. No sentido da exclusão, ainda maior é o problema vivido em situações decisivas na vida dos solicitantes, atreladas a suas novas identidades. Quando uma pessoa cruza a fronteira e carrega um novo documento, assume um novo papel e passa a ser enxergada de acordo com o que o descreve em um documento, tornando-se alvo de exclusões "justificadas" pelo status de solicitante, a quem são conferidos caracteres temporários e vulneráveis. O uso de um documento com o título do refúgio produz dificuldades práticas, como as do emprego.

Segundo o testemunho de outra solicitante, portadora do Protocolo Provisório ${ }^{4}$, que buscou trabalho como manicura em um salão de beleza. A solicitante reportou que, ao apresentar como documento de identidade o Protocolo e sendo perguntada, pela posse desse documento, sobre seu destino temporal próximo no Brasil, não pode responder quanto tempo poderia trabalhar, por que não sabia quanto tempo diriam a ela que ela poderia ficar. O empregador então justificou que, mesmo com a carteira de trabalho, não contrataria alguém que poderia ser obrigada a ir embora no dia seguinte do país, justificativa essa que a solicitante concordou ser válida. Afirmou ser necessária alguma forma de explicação, algum documento, que pudesse esclarecer a situação dos solicitantes, pedindo, formalmente, que a eles não fosse negado trabalho pela incerteza de seu futuro. Ela, bastante emocionada, reportou as dificuldades enfrentadas nesse período e declarou, "se já não sabem o que é

\footnotetext{
4 Documento portado pelos solicitantes de refúgio durante o processo, antes de receber o deferimento ou indeferimento de status de refugiado.
} 
refugiado, mais ainda não sabem o que são solicitantes de refúgio" e que tinha medo por que muitas pessoas acabaram entrando no trabalho informal (Lacerda, 2013, p. 68).

Vemos que a questão das identidades não é problemática apenas no nível de discursos e teorias. As identidades são vividas, praticadas, propostas, aceitas e rejeitadas, e elas, já no papel dado pelo representante soberano, se manifestam e decidem destinos.

Tendo aqui exposto dois lados do encontro entre o solicitante de refúgio e os cidadãos, no caso brasileiro, é necessário partir para "resoluções". A situação vivida por essas pessoas não é normal, nem deve ser normalizada. A exclusão, a negação de oportunidades e a vulnerabilidade são práticas constantes de afirmação de uma identidade coletiva a partir da negação do outro. A negação da cidadania faz do outro um não brasileiro, alguém que precisa ser rejeitado. Além de não ser "um de nós", não contribui para o crescimento do país e é apenas "mais um miserável”. Esse tipo de noção de pertencimento, alimentado por uma afirmação patriótica às custas da negação de pessoas estrangeiras (além do racismo mascarado) não é necessária nem tampouco natural, podendo e devendo ser resistida. Tal mudança, porém, parece tarefa impossível aos que obliteram questionamentos sobre a construção do Estado, sobre a formação de uma identidade coletiva e sobre práticas de poder que moldam o cotidiano das relações sociais.

Essa invisibilidade das vozes de pessoas que trespassam as fronteiras diante do monólogo da política moderna fundado na soberania produz lacunas na cidadania. Essas lacunas se reproduzem como um obstáculo à luta dos refugiados e de outras pessoas por direitos num Estado territorial crescentemente contestado como lócus da vida política contemporânea. Esse bloqueio simbólico se reflete de forma notável na produção de conhecimento sobre os refugiados - 
por vezes, aparece até mesmo em análises que se pretendem críticas nas relações internacionais e nas ciências sociais como um todo.

Esse é o caso da perspectiva de Anne Tickner, autora que utiliza perspectivas feministas para compreender as identidades contemporâneas. Tickner aponta que identidades são pensadas via hierarquias que caracterizam figuras masculinas como presentes e dotadas de uma integridade de características e que, em contraste, apontam figuras femininas como ausentes e carentes. A autora ressalta justamente a presença de identidades e diferenças em nosso cotidiano, elementos esquecidos porém reificados na constante reconstrução de Estados soberanos. Tickner apresenta a construção dessa posição identitária privilegiada masculina, mostrando como o processo de construção do Estado está associado à construção do homem moderno - soberano, autônomo, responsável pela criação do contrato social

74 e pelo estabelecimento da convivência no âmbito do público (Tickner, 1996, p. 148). São essas noções sobre masculino/feminino que construíram e constantemente exercem e representam um Estado visto como estático, uma nação que homogeneíza identidades, reforçando as relações com a diferença (Tickner, 1996, p. 156).

Vendo a dicotomia de gênero como problema central, Tickner acha importante propor uma solução para essa desigualdade simbólica. Mantendo o Estado como cerne da política, ela propõe a reconceituação das identidades estatais de forma que não estejam mais associadas ao militarismo, à masculinidade do patriotismo, buscando um conceito reformulado de cidadania, em que não haja protetores / protegidos, mas defensores (Tickner, 1996, p. 160). Sua busca por mudanças passa pelo desvelamento desse masculino no topo hierárquico e pela reinvenção da identidade cidadã a partir da negação da hierarquia e da inserção do feminino nos espaços da política. 
Ao mesmo tempo que perfaz uma profunda crítica ao androcentrismo das relações internacionais, o argumento de Tickner reproduz outras desigualdades. Ao transpormos sua análise para outras categorias de enfrentamento de identidades - como a do cidadão e do solicitante de refúgio -, vemos que, ao manter a centralidade da identidade cidadã, essa estratégia reitera exclusões e bloqueia transformações. Como ressaltado por estudos críticos sobre refugiados, a cidadania é fator central para a construção da exclusão, a partir da oposição hierárquica cidadão/refugiado. O refugiado é necessário para a criação do não refugiado tanto quanto o cidadão é necessário para a criação do refugiado, “o 'nós' está totalmente ligado e é formado por sua relação com o "outro" (Haddad, 2008, p. 54). Essa desigualdade entre cidadãos e alienígenas é o fulcro da política moderna.

Indo além de Tickner, que adota como identidade central a cidadania, nos propomos a repolitizar a cidadania, deslocando-a do posto privilegiado de referência, como normalidade e verdade. Nesse sentido, nossas considerações finais recuperam a crítica feita no curso do artigo por Connolly às identidades modernas como coesas, coerentes e homogêneas - e a tentativas de reformular essas identidades em termos de gênero, mas mantendo-as coesas, coerentes e homogêneas (e distantes de pessoas cujos direitos cidadãos permanecerão precarizados e no limbo simbólico entre soberanias, caso dos refugiados), como a proposta de Tickner.

A contingência trazida pela crítica de Connolly consegue preencher lacunas evidenciadas na proposta de Tickner por autoras como Emma Haddad (2008) e Seyla Benhabib (2004, p. 11), para quem "Uma série de contradições internas entre os direitos humanos universais e a soberania territorial está construída na lógica da maioria dos nossos mais amplos documentos de direito internacional”. 
A contingência se coaduna com a complexidade de encontros cotidianos fundados na fronteirização soberana que impactam as vidas de solicitantes de refúgio e imigrantes (legais ou não).

$* * *$

Para pensar o lugar da identidade cidadã de forma a operar uma mudança nas relações assimétricas de poder embutidas nos processos de fronteirização associados ao refúgio, a proposta de William Connolly referente à ambivalente "descoberta" da América como encontro identitário se mostra mais incisiva do que a proposta de Tickner. $\mathrm{O}$ autor afirma que identidade é algo necessário, que provém o caminho de interação com o outro, o que implica uma constante redefinição do eu, necessário para o viver político. Porém, é preciso que não se estipule uma identidade como verdadeira, é preciso viver sempre na tentativa de refutar essa colocação, mantendo sempre nas interações e no encontro com a diferença a consciência de que "nenhuma identidade é a identidade verdadeira, pois toda identidade é particular e contingente" (Connolly, 1989, p. 331). A busca de um chão perene para identidades é vã. Ao buscar fixá-las, "eppur si muove”.

A proposta de Connolly é bastante útil para pensar o encontro entre o imigrante, seja refugiado, solicitante, ou ilegal, e o cidadão, a partir do questionamento sobre o "chão" da identidade, enfatizando a construção de identidades como performances em um chão que sempre se move (Hekman, 2000). Questionando a veracidade e perenidade das identidades, teríamos chances de desestabilizar o padrão de relacionamento com a diferença e mudar o tipo de encontro com o outro, criando novas possibilidades políticas que abrangem inclusão e diálogo, inviabilizando formas de rejeição, preconceitos e mitigando exclusões, que em nada contribuem com a situação atual de um Brasil que recebe cada vez mais pessoas d'alhures. 
"Vivemos em um mundo de novas e já estabelecidas inclusões e exclusões; em um mundo de mais fronteiras e mais soberanias, e não menos" (Walker, 2005, p. 23). É preciso lidar com esse movimento em termos de pesquisa e em termos políticos. A situação de refugiados e migrantes no Brasil toma espaço na grande mídia, as pessoas dão suas opiniões e mostram os caminhos que deveriam ser traçados. É possível - e desejável - estabelecer formas alternativas de lidar com diferenças construídas, que não termine no circuito violento dos centros de detenção. Sobremaneira, nos termos de Connolly, é preciso repensar a própria concepção de identidade antes de se posicionar sobre outros ou imputar a esses expectativas e temores que podem ser resistidos e que podem revelar bastante sobre nossas autoconcepções como cidadãos, brasileiros e humanos.

\section{Ana Luiza Lacerda}

é mestranda em Relações Internacionais na Pontifícia Universidade Católica do Rio de Janeiro (PUC-Rio).

\section{Carlos Frederico P. S. Gama}

é professor de Relações Internacionais na Universidade Federal do Tocantins (UFT).

\section{Bibliografia}

ACNUR. 2012. Convenção Relativa ao Estatuto dos Refugiados. Lei n 9.474/97. Coletânea de Instrumentos de Proteção Internacional de Refugiados e Apátridas. 4. ed. Brasília: ACNUR/IMDH.

AMARAL, E. F. L.; FUSCO, W. 2005. "Shaping Brazil: the role of international migration". Migration Information Source. Disponível em: <http://www. researchgate.net/profile/Wilson_Fusco/publication/265989240_ Shaping_Brazil_The_Role_of_International_Migration/ links/54b95d860cf2d11571a44a39.pdf>. Acesso em: 21 set. 2015.

BENHABIB, S. 2004. The rights of others: aliens, residents, and citizens. Cambridge: Cambridge University Press.

BETTS, A. A.; LOESCHER, G. 2011. Refugees in international relations. New York: Oxford University. 
BIGO, D. 2002. "Security and immigration: toward a critique of the governmentality of unease”. Alternatives: Global, Local, Political, n. 27, pp. 63-92.

BRASIL. Lei $n^{\circ} 9.474$, de 22 de julho de 1997. Define mecanismos para a implementação do Estatuto dos Refugiados de 1951, e determina outras providências.

CAMPBELL, D. 1996. "Violent performances: identity, sovereignty, responsibility”. In: LAPID, Y. (ed.). The return of culture and identity in IR theory. Boulder: Lynne Rienner Publishers.

CERVO, A. L. 2002. "Relações internacionais do Brasil: um balanço da Era Cardoso". Revista Brasileira de Política Internacional, v. 45, n. 1, pp. 5-35.

CONNOLLY, W. E. 1989. "Identity and difference in global politics". In: DERIAN, J.; SHAPIRO, M. J. (eds.). International/intertextual relations: postmodern readings of world politics. Toronto: Lexington Books.

EDKINS, J.; PIN-FAT, V. 2005. "Introduction: life, power, resistance”. In: EDKINS, J. et al. Sovereign lives: power in global politics. New York: Routledge.

FOUCAULT, M. 1982. "The subject and power". Critical Inquiry, v. 8, n. 4, pp. 777-95.

2010. Microfísica do poder. São Paulo: Martins Fontes.

GAMA, C. F. P. S. 2015. "14 anos de silêncio: a 'Guerra ao Terror' e a tragédia dos refugiados no Oriente Médio”. Blog SRZD, 11 set. Disponível em: <http://www.sidneyrezende.com/noticia/254709>. Acesso em: 5 jan. 2016.

GAMA, C. F. P. S.; TABAK, J. 2012. Modernity at risk: complex emergencies, humanitarianism, sovereignty. Saarbrücken: LAP - Lambert Academic Publishing.

HADDAD, E. 2008. The refugees in international societies. Cambridge: Cambridge University Press.

HEKMAN, S. 2000. "Beyond identity - feminism, identity and identity politics". Feminist Theory, v. 1, n. 3, pp. 289-308.

HINDESS, B. 2005. "Citizenship and empire". In: HANSEN, T. B.; STEPPUTAT, F. (eds.). Sovereign bodies: citizens, migrants, and States in the postcolonial world. Princeton: Princeton University Press.

HOBBES, T. 1991 [1642-1651]. O Leviatã. São Paulo: Saraiva.

HYNDMAN, J. 2000. Managing displacement: refugees and the politics of humanitarianism. Minneapolis: University of Minnesota Press.

JUBILUT, L. L. 2006. "Refugee law and protection in Brazil: a model in South America?”. Journal of Refugee Studies, v. 19, n. 1, pp. 22-44. . 2007. "O procedimento de concessão de refúgio no Brasil".

Disponível em: <www.portal.mj.gov.br>. Acesso em: 5 mar. 2013. 
JUBILUT, L. L.; APOLINÁRIO, S. M. O. S. 2008. "Refugee status determination in Brazil: a tripartite enterprise”. Refuge, v. 25, n. 2, pp. 29-40.

LACERDA, A. L. 2013. Os processos de solicitação de refúgio no Brasil. Trabalho de Conclusão de Curso em Relações Internacionais. Rio de Janeiro: PUC.

LELANDAIS, G. E. 2008. "Paris Sciences Po - IPS Conference, October 26-27, 2007”. International Political Sociology, n. 2, pp. 254-64.

LESSER, J. 1994. "Immigration and shifting concepts of national identity in Brazil during the Vargas Era”. Luso-Brazilian Review - Getulio Vargas and His Legacy, v. 31, n. 2, pp. 23-44.

MALKKI, L. 1996. "Speechless emissaries: refugees, humanitarianism, and dehistoricization”. Cultural Anthropology, v. 11, n. 3, pp. 377-404.

MOREIRA, J. B. 2005. "A problemática dos refugiados na América Latina e no Brasil”. Cadernos PROLAM/USP, ano 4, v. 2, pp. 57-76.

2007. "O acolhimento dos refugiados no Brasil: políticas, frentes de atuação e atores envolvidos”. Disponível em: <http://www.abep.nepo. unicamp.br/docs/anais/outros/5EncNacSobreMigracao/comunic_ sec_2_aco_ref_bra.pdf>. Acesso em: 7 jan. 2016.

2010. "Redemocratização e direitos humanos: a política para refugiados no Brasil”. Revista Brasileira de Política Internacional, v. 53, n. 1, pp. 111-29.

MOREIRA, J. B.; BAENINGER, R. 2010. "Local integration of refugees in Brazil”. Forced Migration Review. Disponível em: <http://www.fmreview. $\mathrm{org} / \mathrm{fr} /$ node/1222>. Acesso em: 21 set. 2015.

MOULIN, C. 2011. "Os direitos humanos dos humanos sem direitos. Refugiados e a política do protesto”. RBCS - Revista Brasileira de Ciências Sociais, v. 26, n. 76, pp. 145-55.

MOULIN, C.; NYERS, P. 2007. "'We live in a country of UNHCR' - refugee protests and global civil society”. International Political Sociology, v. 1, n. 4, pp. 356-72.

SOGUK, N. 1999. States and strangers: refugees and displacements of statecraft. Minneapolis: University of Minnesota Press. 2007. "Border's capture: insurrectional politics, bordercrossing humans, and the new political”. In: RAJARAM, [Prem] K.; GRUNDY-WARR, C. (eds.). Borderscapes: hidden geographies and politics at territory's edge. Minneapolis: University of Minnesota Press.

TICKNER, J. A. 1996. "Identity in international relations theory: feminist perspectives". In: LAPID, Y. (ed.). The return of culture and identity in IR theory. Boulder: Lynne Rienner Publishers. 
VERWEY, A. et al. 2000. "A percepção brasileira dos refugiados". Revista Brasileira de Política Internacional, v. 43, n. 1, pp. 183-85.

WALKER, R. B. J. 1993. Inside/outside: international relations as political theory. Cambridge: Cambridge University Press. . 2005. "International, imperial, exceptional: with but mainly against Kant”. Paper apresentado no International Studies Association Meeting, Honolulu, Hawai'i, março. 


\section{O SOLICITANTE DE REFÚGIO E A SOBERANIA MODERNA: A IDENTIDADE NA DIFERENÇA}

\section{ANA LUIZA LACERDA \\ CARLOS FREDERICO P. S. GAMA}

Resumo: Neste artigo, abordamos a questão da identidade do solicitante de refúgio. A partir dos conceitos de soberania e fronteira (centrais nos debates das relações internacionais sobre identidade e diferença), investigamos formas de violência e exclusão que envolvem as relações do solicitante de refúgio. Observando seu cotidiano, analisamos como se dá a construção da nova identidade, formada no encontro com a diferença. Uma identidade que exige constante negociação desde o momento em que cruza a fronteira. Dois momentos do percurso do solicitante são abordados: o cruzamento da fronteira com a declaração de uma nova identidade; e as experiências cotidianas enfrentadas por essas pessoas, com base em depoimentos de solicitantes de refúgio no Brasil.

Palavras-chave: Solicitante de Refúgio; Fronteiras; Soberania; Identidade; Diferença.

\section{ASYLUM SEEKERS AND MODERN SOVEREIGNTY: IDENTITY IN DIFFERENCE}

Abstract: In this article, we analyse the issue of identity of asylum seekers. We start with the concepts of sovereignty and borders (crucial to International Relations debates on identity and difference) in order to investigate modalities of violence and exclusion embroiled in the social relations of asylum seekers. We analysed the construction of her/his identity through everyday life encounters with difference. The article emphasizes the continuous negotiations of identity that asylum seekers experience since a border is crossed. We highlight two steps of those processes: firstly, the crossing of borders that implicates the declaration of a new identity; secondly, the everyday struggles 
that such persons indulge in, filtered through the testimonials of asylum seekers in Brazil.

Keywords: Asylum Seekers; Borders; Sovereignty; Identity; Difference. Recebido: 04/12/2014 Aprovado: 04/12/2015 